\title{
Integration of Well Logs and Seismic Attribute Analysis in Reservoir Identification on PGS Field Onshore Niger Delta, Nigeria
}

\section{Okpoli C. C.*, Arogunyo D. I}

Department of Earth Sciences, Faculty of Science, Adekunle Ajasin University, PMB 1, Akungba-Akoko, Ondo State, Nigeria. *Corresponding author email: cyril.okpoli@aaua.edu.ng

\section{DOI: 10.2478/pjg-2020-0002}

\section{Abstract:}

Integrated well dataset and seismics delineated the PGS field onshore Niger Delta for reservoir identification. Gamma ray, resistivity, Neutron and density Logs identified four lithologies: sandstone, shaly sandstone, shaly sand and shale. They consist of sand-shale intercalation with the traces of shale sometimes found within the sand Formation. Petrophysical parameters of the reservoirs showed varying degree of lower density, low gamma ray, high porosity and resistivity response with prolific hydrocarbon reservoir G due to its shale volume and the clean sand mapped as a probable hydrocarbon reservoir. 3D seismic data located both seismic scale and sub-seismic scale structural and stratigraphic elements. Risk reduction in dry hole drilling due fault missing in conventional seismic attribute analysis and interpretation, have to be integrated into the Oil companies standard practice.

Keywords: Petrophysics, seismics, reservoir, structural, stratigraphic

\section{Introduction:}

Characterizing a reservoir is used for the quantification of reservoir with the reduced level of uncertainty associated with the geological models of different exploration and production interest. Applications of well-log measurements is for the evaluation of the porosities and saturations of reservoir rocks, and for depth correlations. Lately, there has been an increasing appreciation of the value of log data as a source of more general geological information Geologists have realized in fact, that well-logs can be to the subsurface rock what the eyes and geological instruments are to the surface outcrop. Through logging we measure a number of physical parameters related to both the geological and petrophysical properties of the strata that have been penetrated; properties which are conventionally studied in the laboratory from rock-samples [1].

In addition, logs tell us about the fluids in the pores of the reservoir rocks. The rather special kind of picture provided by logs is sometimes incomplete or distorted, but always permanent, continuous and objective. It is an objective translation of a state of things that one cannot change the statement of a scientific fact. Log data constitute, therefore, a "signature" of the rock; the physical characteristics they represent are the consequences of physical, chemical and biological (particularly geographical and climatic) conditions prevalent during deposition; and its evolution during the course of geological history. Log interpretation should be aimed towards the same objectives as those of conventional laboratory core-analyses. Obviously, this is only feasible if there exist well-defined relationships between what is measured by logs, and rock parameters of interest to the geologist and reservoir engineer.

Describing reservoir dynamics quantitatively and its properties using well logs, seismic and geological datasets do aid the economics of reservoir development and enhancement of its production. In the majority if reservoir development projects, the description of the reservoir is achieved through integrating well information and well logs. The knowledge of reservoir dimension is an important factor in quantifying producible hydrocarbon reservo ir and the needed information includes the thickness and the extent of the reservoir [2]. These parameters are important are important because they serve as veritable inputs for reservoir volumetric analysis. To determine reservoir thickness well logs, particularly using the gamma ray and the resistivity logs are acquired for that purpose. All oil and gas produced are connected to accumulation in pore spaces of lithology like sandstone.

While the seismic method provides indirect measurements in the form of seismic records. The word indirect is inappropriate because the seismic method uses a non-invasive technique (seismic waves and seismic recording instruments) to penetrate and record data from a remote body (the underground rocks). Similar techniques are radar, sonar, and ultrasonic medical imaging. Seismic images are made up of signals called traces, records the reflection of the seismic waves from the boundaries of different rock layers. Such rock-layers boundaries are called interfaces (or horizons). In some cases, horizons are approximately horizontally planar surface with low to moderate dips. In other cases, horizons are curved a contorted surface with steep dips.

Identification and adequate quantification of hydrocarbon bearing reservoir properties or the characterization of their prospects in other to determine their economic worth is a problem facing the oil and gas industry. The objectives of subsurface petroleum geology are to find and develop oil and gas. These objectives are best achieved by the use and integration of all available data and correct application of these data in which subsurface geophysical maps are perhaps the most the important vehicle used to explore undiscovered hydrocarbons and to develop proved hydrocarbon reserves [3].

Reserves are those quantities of petroleum which are anticipated to be recovered commercially from the known accumulations. All estimated reserves involve some degree of uncertainty which depends mainly on the amount of reliable geologic and engineering data available at the time of the estimate and the interpretation of the data. Hydrocarbons are formed in geologic traps which are combinations of rock structures that will keep them from migrating either vertically or horizontally [4]. Majority of the traps in the Niger Delta are structural, to locate them, horizons are picked and fault mapped at seismic in lines and crossline. The aim of this paper is to delineate hydrocarbon using the integration of both the seismic and well log techniques.

\subsection{Regional Geology}

The area of study is a PGS field located in the Niger Delta region of Nigeria (Figure 1). It is an onshore oil field. There are restraints in the determination of the location of the field, since it was not provided from the data source.

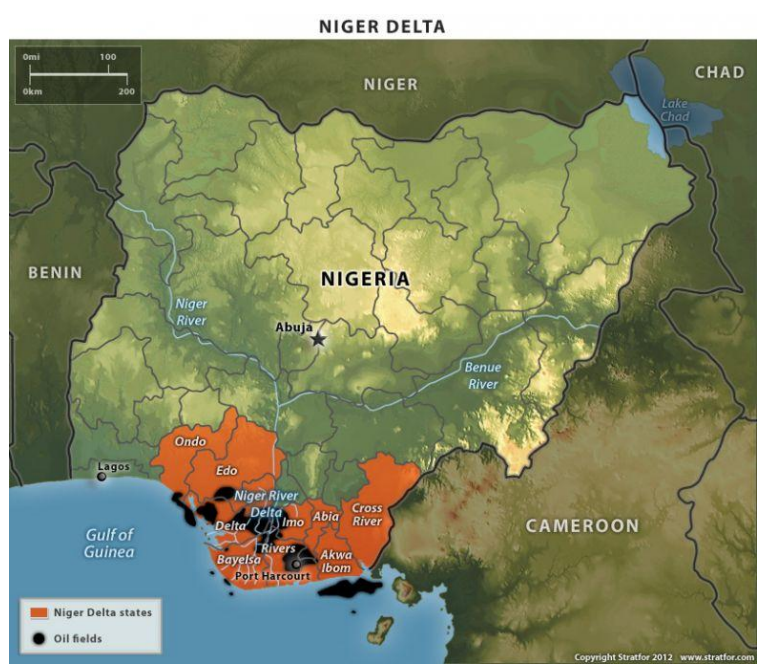


Figure 1: Location of the study area

\subsection{Geology of the Niger Delta}

Niger delta is situated in the Gulf of Guinea and extends throughout the Niger Delta Province (Figure 2) [5-7]. From the Eocene to the present, the delta has prograded south-westward, forming depobelts that represents the most active portion of the delta at each stage of its development [8]. These depobelts form one of the largest regressive deltas in the world. Present in the Niger Delta petroleum system is the Tertiary Niger Delta (Akata-Agbada) petroleum system. The primary source rock is the upper Akata formation, the marine-shale facies of the delta, with possibly contribution from interbedded marine shale of the lowermost Agbada formation. Oil is produced from the sandstone facies within the Agbada formation, however, turbidite sand in the upper Akata formation is a potential target in deep water offshore and possibly beneath currently producing intervals onshore [9].

The Niger Delta is situated on the continental margin of the Gulf of Guinea between latitude $30 \mathrm{~N}$ and $60 \mathrm{~N}$ and longitude $50 \mathrm{E}$ and $80 \mathrm{E}$. It was formed at the site of a rift triple junction related to the opening of the south Atlantic starting in the late Jurassic and continuing into the Cretaceous. The onshore section of the Niger Delta region is described by the southern Nigeria and southwestern Cameroon geology. The northern boundary is the Benin flank; an eastnortheast trending hinge line south of the West Africa basement massif [10]. The north-eastern boundary is defined by outcrops of the Cretaceous on the Abakaliki High and further east-south-east by the Calabar flank: a hinge line bordering the adjacent Precambrian. The offshore boundary of the province is defined by the Cameroon volcanic line of the east, the eastern boundary of the Dahomey basin (the eastern-most West African transform-fault passive margin) to the west, and $2 \mathrm{~km}$ sediment thickness contour or the 4000-meter bathymetric contour in areas where the sediment thickness is greater than two kilometres to the south and south west [11]. The province convers 300,000 km 2 and includes the geologic extent of the Tertiary Niger Delta (AkataAgbada) petroleum system.

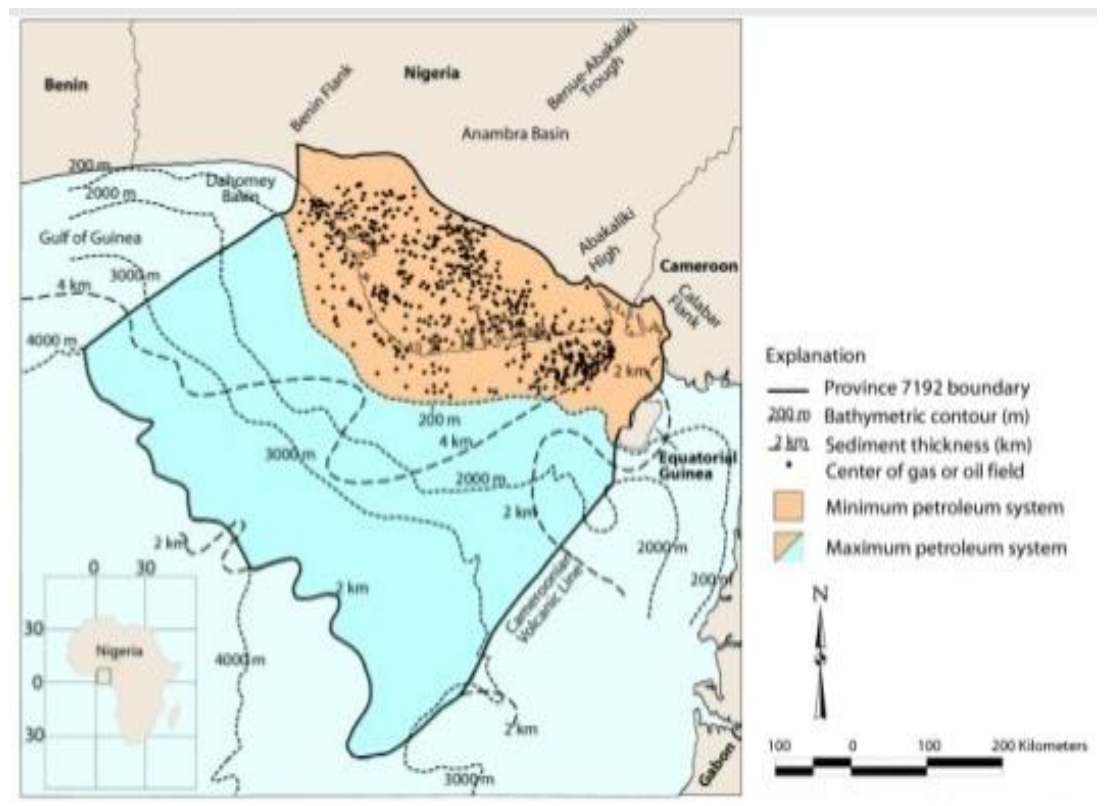

Figure 2: Niger Delta map illustrating the petroleum system and its structural features

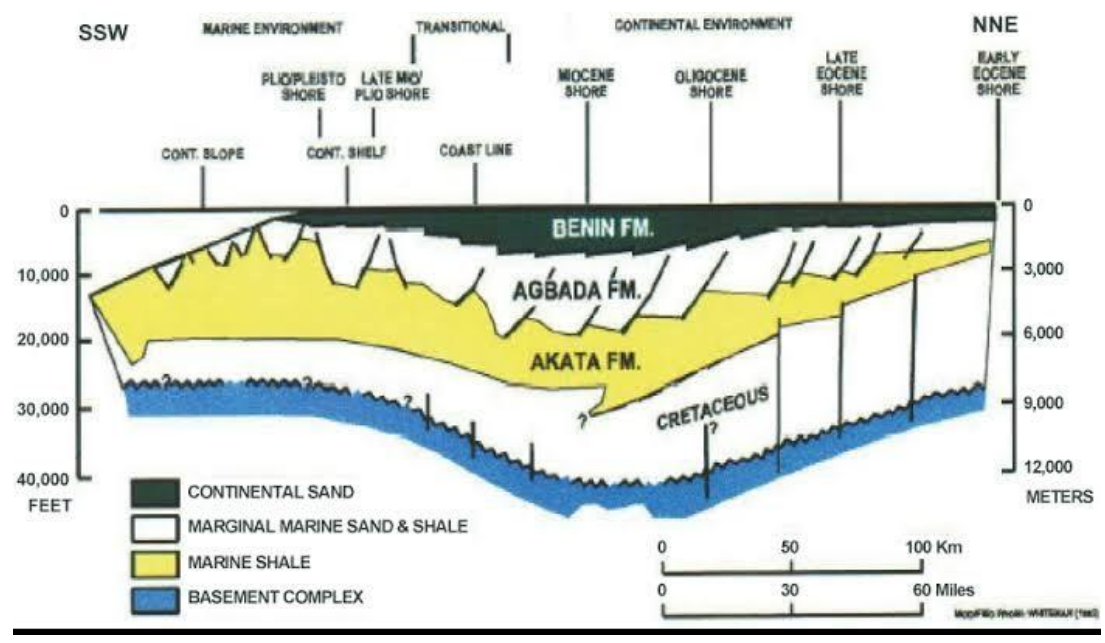

Figure 3: The stratigraphy formed by a prograding sequence of offlaps cycles with three distinct transgressive lithologic units.

The Niger Delta is a region regressive sequence of clastic sediments developed in a series of flap. All deep wells in the basin documents tripartite lithostratigraphic succession in which the regressive sequence is demonstrated (Figure 3). The prograde of the deltaic sequence has been controlled by syn-sedimentary faults and interplay between subsidence and sediment supply. The delta can be divided into a number of major growth fault bounded sedimentary unit or depobelts, which as the delta prograde succeeded one another in a southward direction in Nigeria, the trend has been referred to in the literature as mega structures or depobelts [12]. The inter digitization of a small number of lithofacies makes it possible to determine the unit and boundaries of sufficient integrity to constitute separate locations in a formal sense. However, three formations named (Agbada, Akata formation) are widespread use [6,7]. Corresponding to portions of the tripartite sequence distinguished on the basis of sand shale.

The Akata formation is the base of sedimentary formation in the Niger delta. This formation is characterized by shale deposits. The shale here is generally dark grey, and in some places sandy and silty. Occasional traces of the plant remain and mica have been found in the upper part of the Formation. The Formation is thought to be main source rock for the Niger Delta oil and gas, because it is rich in micro-fauna and the planktonic foraminifera assemblage indicates Akata sediment deposition on a shallow marine shelf. The thickness of this sequence is estimated at about $7000 \mathrm{~m}$ in the central part of the Delta 
[8]. Marine shale from the base of the sequence in each depobelt, range from the Paleocene to Holocene in age. The Formation lies beneath the diapirs, and high-pressure zone on large scale. It underlies the entire delta, and typically over pressured.

The Agbada Formation is the lithologic unit directly overlying the Akata formation. Agbada Formation has the adequate presence of fossils which serves as good source rocks $[9,10]$. It is characterized by the intercalation of sandstone's and shale in various proportions and thickness, representing cyclic sequences of the off-lap unit. These paralic elastics are truly deltaic portion of the sequences and were deposited in a number of deltaic-front, delta-topset and fluvial-deltaic environments. The alternation of fine and coarse clastic provide multiple reservoirs - seal couplets. The paralic sequence is present in all depobelts, and ranges in algae from the Eocene to Pleistocene. It consists of paralic siliciclastic over $3700 \mathrm{~m}$ thick and represents the actual deltaic portion sequence (Figure 4).

The Benin Formation consists mainly of fresh water, fluviatile sands and some gravels occasioned by the inter-spread with shale beds towards the base of the rock-units. Benin sands are fine to coarse grained and very poorly sorted; they are sub angular to well-rounded and mostly clear white to yellowish brown in colour. The sands and gravels of the formation were deposited as a point bars by a graded channel stream as naturally filled while the finer deposits were laid in back swamps and lakes. The oldest continental sands are probably Oligocene, although they lack fauna and area impossible to date directly. Offshore they became thinner and disappear near the shelf edge. Although these three formations have been identified as Formation, they are distinguished only be a number of vague characteristics, the most important of which is sand-shale ratio [6]

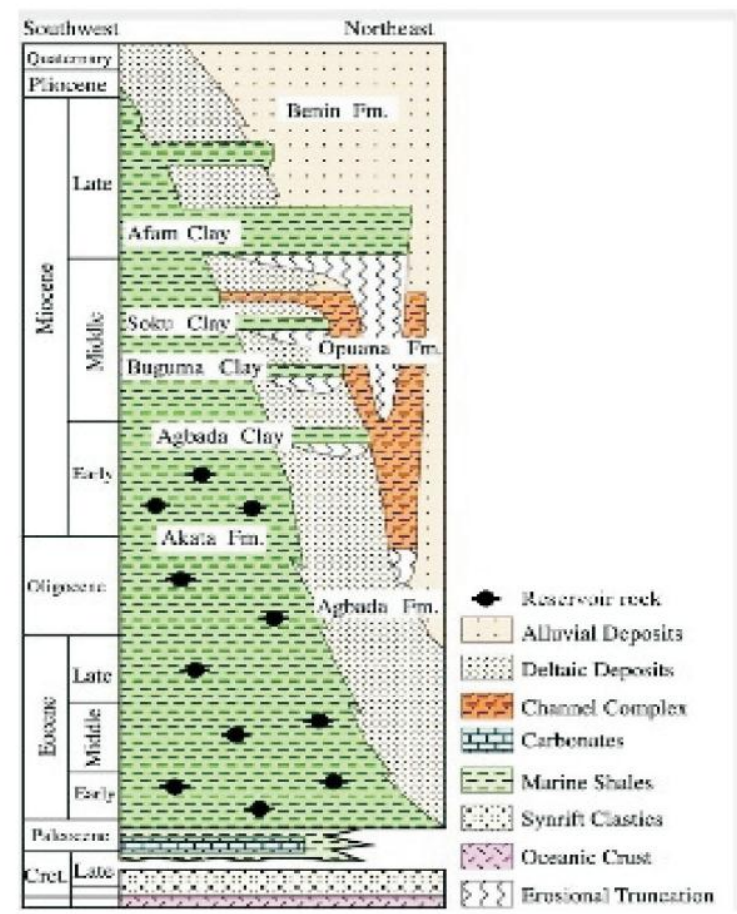

Figure 4: Stratigraphic column showing the three formations of the Niger Delta $[8,11]$.

Group of researchers proposed that peak of recent oil window in the Niger Delta is $240^{\circ} \mathrm{F}\left(115^{\circ} \mathrm{C}\right)$ isotherm [12]. Northwestern section of the Niger delta, the oil window (active source-rock interval) is situated in the upper Akata Formation and the Lower Agbada Formation as shown in Figure 5 while the southeast section is up to 4000' below the upper Akata/lower Agbada sequence [12]. Some researchers characterised the distribution of the top of the oil window to the sand/shale thickness ratios and the overburden rock i.e differential proportions of Benin and Agbada Formation [6,10,13]. Benin Formation which is made up of continental sand has the lowest thermal gradient (I. 3 to I / $8{ }^{\circ} \mathrm{C} / 100 \mathrm{~m}$ ); the paralic Agbada Formation has an intermediate gradient $\left(2.7^{\circ} \mathrm{C} / 100 \mathrm{~m}\right)$; while the over-pressured marine Akata Formation has the highest $\left(5.5^{\circ} \mathrm{C} / 100 \mathrm{~m}\right)[14]$.

Consequently, the depobelt is hinged on the depth to any temperature owed to the gross distribution of sand and shale. Thus, sand/shale ratios were the only variable, the distal offshore sub surface temperatures would be elevated because sand percentages are lower. To the contrary, the depth of the hydrocarbon kitchen is expected to be deeper than in the delta proper, because the depth of oil generation is a combination of factors (temperature, time, and deformation related to tectonic effects) [15].

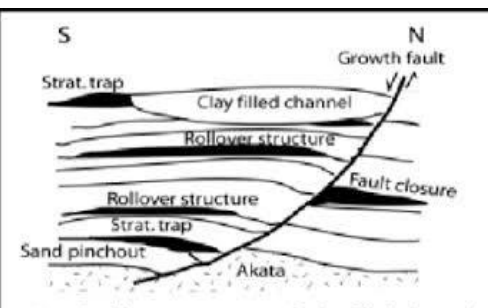

Simple rollover structure with clay filled channel

S

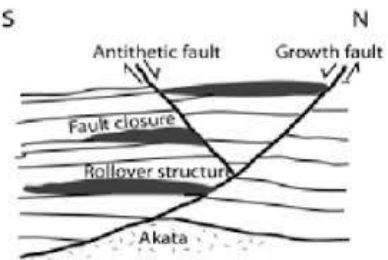

Structure with antithetic fault

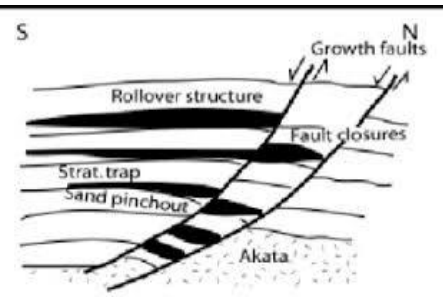

Structure with multiple growth faults

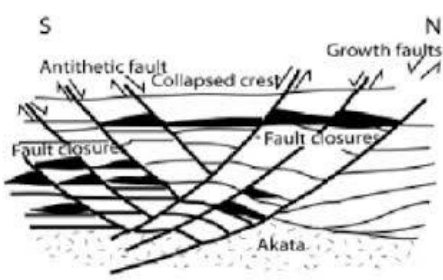

Collapsed crest structure 
Figure 5: Field structural styles and traps in the Niger Delta [8,13]

Matured over-pressured shales migration in the more distal portion of the Niger delta, suggested same of the over-pressured shales in the Gulf of Mexico. Hunt, relates episodic expulsion of petroleum from abnormally pressured, mature source rocks to fracturing and resealing of the top seal of the overpressured interval [16]. In rapidly sinking basins, such as the Gulf of Mexico, the fracturing/resealing cycle occurs in intervals of thousands of years. This type cyclic expulsion is certainly plausible in the Niger Delta basin where the Akata Formation is over-pressured. Beta and Oti, predict a bias towards lighter hydrocarbons (gas and condensate) from the over-pressured shale as a result of down-slope dilution of organic matter as well as differentiation associated with expulsion from over-pressured sources [15]

\subsection{Materials and Methodology}

\subsection{Materials}

The material provided for the study include: Seismic data of the area (3D) with good resolution processed as 32-bit integer, Well data (LAS files) for four wells named PGS 5, PGS 7, PGS 10,PGS 11, checkshot data for PGS 11, and Well deviation data for PGS 5, PGS 7, PGS 10,PGS 11. The dataset was loaded into the interactive tools of the Schlumberger Petrel software, with the interpretation of well data from correlation to evaluation and the results integrated into the seisimic data using the available checkshot data. Seven hydrocarbon bearing reservoirs were studied on this field and were mapped across the field. Time and depth structure maps were generated from the interpretation. Seimsic attributes such as the variance, impedance, root mean square,amplitude were extracted. The extracted attributes were analyzed and it was discovered the variance attribute showed better response to faults than any other attribute used for the study.

\subsection{Methodology}

The methodology of this research work involves data gathering and analysis of the data using PetrelTM software by Schlumberger. The SEG-Y format 3D seismic data consists of in lines and crosslines. Horizons are usually picked based on the prospective zones identified from the petrophysical analysis of the well logs. Tops and bases of these horizons were mapped and correlated across the available wells. The correlation was done using the gamma-ray and resistivity logs.

Series of volume attributes used were variance edge and sweetness attributes visualized in Schlumberger Petrel software interface ran on the 3D seismic volume data to investigate potential structural and stratigraphic controls within the study area. Similarly, surface attributes including the interval average, arithmetic, acoustic amplitude, lower loop area interval mean were run on the horizon surfaces to generate the attributes maps and gain full understanding of the target features in terms of porosity, permeability and direct hydrocarbon indicators (DHI) for hydrocarbon exploration in the area.

\subsubsection{Seismic processing}

We make use of these processing steps:

- Fourier transformation: here the signal is changed from time to the frequency domain.

- Convolution/deconvolution processes permit the determination of the effect of the Earth on the seismic signal.

- Frequency filtering were used to manage the data output from the data input.

- The data are zero phased such that a consistent output results from the addition of waveforms. For example, the addition of equal signals that are completely out of phase will result in no signal.

- Common depth point stacking, which involves the arrangement of component data for single depth point side by side.

- Muting of the first refraction breaks reduces the masking of weak shallow reflections.

- Migration. Provided that the velocity only varies with depth (i.e., not laterally), the travel time for a diffraction is at a minimum directly above the point of diffraction.

Clearly, the Earth rarely behaves with such simplicity. In consequence, migration is designed to restore seismic reflectors to their proper $\mathrm{x}-\mathrm{y}$ position Most seismic interpretations are made on sections or volumes in which the $\mathrm{x}$ and $\mathrm{y}$ dimensions are measured in space and the vertical, $\mathrm{z}$, direction in time (strictly, two-way time). Depth-migrated data incorporates vertical and spatial variation in the velocity of the Earth's subsurface. Transformation of time to depth is of critical importance: many "exciting prospects" have turned out to be unreal simply products of high-velocity rock causing underlying rock to be pulled up on a two-way time display.

\subsubsection{Seismic attributes analysis}

The goal of seismic attribute analysis is to improve the spatial prediction of structural and stratigraphic features as well as petrophysical and geomechanical properties throughout the reservoir. Key to analysis is discovering the linear and non-linear relationship between the seismic trace and production indicators. Use of seismic attributes for reservoir characterization has been commonplace for many years. Seismic data provides important structural and stratigraphic information in three dimensions. Seismic attributes are useful tools for detecting fractures or faults and geological lineaments which are below the seismic resolution (sub-seismic, normally less than 15 meters). Amplitude, phase, and frequency are the main characteristics of seismic traces. Extracting instantaneous and local values of these parameters is useful for revealing subsurface features. In addition to these basic attributes, weighted averaging of instantaneous seismic attributes is beneficial. This technique is most useful for reducing spikes and noise variations.

Among the various seismic attributes, curvature attributes are most useful for detecting structural features. Curvature attributes include both dip and azimuth attributes. They can be classified as either horizon-based or volume-based. Horizon-based curvature is sensitive to the interpreter ability to pick seismic horizons as well as the quality of the seismic data [17]. Volume-based curvature computation is now more popular. In addition to fault and fracture detection by curvature analysis, stratigraphic features can also be recognized through curvature volumetric attributes. This is due to the fact that most of the seismic stratigraphy depends on the morphology of the seismic texture [18]. Higher fracture density can cause heterogeneity in the reservoir zone.

\subsubsection{Determining the production drivers}

Seismic traces are composite responses to geological factors such as lithology, fluid saturations and geomechanical properties. Unravelling the influence each rock property has on the seismic trace and identifying a seismic attribute or combination of attributes which is capable of predicting that property is a mainstay reservoir characterization workflow. Petrophysical property analysis from well logs and core/cuttings gives us insights into what is driving production in the reservoir. Forward modelling is then employed to identify key seismic attributes that distinguish these primary controls on production.

\subsubsection{Inverted-curve-data key attributes interpretation}

Seismic attributes are sensitive to lateral changes in geology so are utilized to assist in mapping facies, reservoir properties and faults. Complex trace attributes help to interpret lateral continuity of stratigraphic events, bedding geometry, and the presence of hydrocarbon. Geometric attributes are used to characterize stratigraphic features and for fault/fracture detection. Time-Frequency attributes of Spectral Decomposition increase the seismic resolution to highlight lateral variability of depositional features and faults. Multi-attribute analysis for rock property prediction. Individual seismic attributes give us indications of many subtle properties, however the real enhancement in predictive accuracy and reliability of results comes from combining multiple 
seismic attributes and solving the non-linear relationship between the seismic attributes and reservoir properties. Multi-linear regression and neural network techniques are employed to determine which seismic attributes should be combined to predict a particular reservoir property. Ultimately, 3D volumes of rock properties or other production indicators are generated. The improved geologic interpretation and prediction of production indicators assist in the identification of preferential drilling locations and completion practices [18].

\subsubsection{Interpretive processing}

This was used in enhancing the images (e.g., the depth-migrated records) provided by seismic processing to better reveal the overall geology or particular aspects of the geology. Interpretive processing comes under the heading of image enhancement. Generally speaking, interpretive processing involves principles of seismic waves and principles of deterministic and statistical imaging and of time-series analysis. The purpose of interpretive software is to do interpretive processing - namely, to convert the image of the geology provided by seismic processing into an enhanced image of that geology. Such enhanced images, which can be displayed on interpretive visualization systems, are used in the final evaluation to determine favourable sites for drilling new oil wells. The enhanced images, within the computer, are in the form of 2D or 3D arrays of data points.

\subsection{Results and Discussion}

The ultimate goals of any reservoir petrophysical analysis are basically to identify reservoirs, delineate them, and determine the distribution of their relevant properties, such as depth, porosity and permeability and so on in order to appropriately define the hydrocarbon bearing capacity of the reservoir. A detailed petrophysical and well log analysis was carried out on each of the reservoirs in each layer. All was done in pursuit of a well-described suit of reservoirs, at least within the depth range of interest. Seismic well attributes were also used in the identification of these reservoirs.

\subsection{Correlation process}

This was based on the gamma ray and resistivity log which was obtained from the wells during drilling. The first stage for this correlation was a visual correlation of the well logs. This was accomplished by preparing a correlation panel, which consists of the different gamma ray logs of each well-arranged horizontally in a logical order i.e. how the wells are distributed in the field. Following this, the logs are aligned with respect to a particular reference datum. The reference datum used is a thick and extensive shale unit. Another step was the assembly of cross section for the correlation. This consist setting the composite logs from various well side by side and using either regular spacing while keeping a reference maker aligning all the wells or using spacing which take into consideration the real distance between wells while restoring a vertical scale relative to sea level.

\subsection{Petrophysical characterization}

Petrophysics is defined as the study of the physical and chemical properties of rocks and their contained fluids, using rock properties and relations among these properties to identify, quantify and evaluate hydrocarbon reservoirs. Petrophysics is an essential tool in any project work aimed at characterizing subsurface reservoirs because it plays a fundamental role in the description, characterization and evaluation of reservoirs.

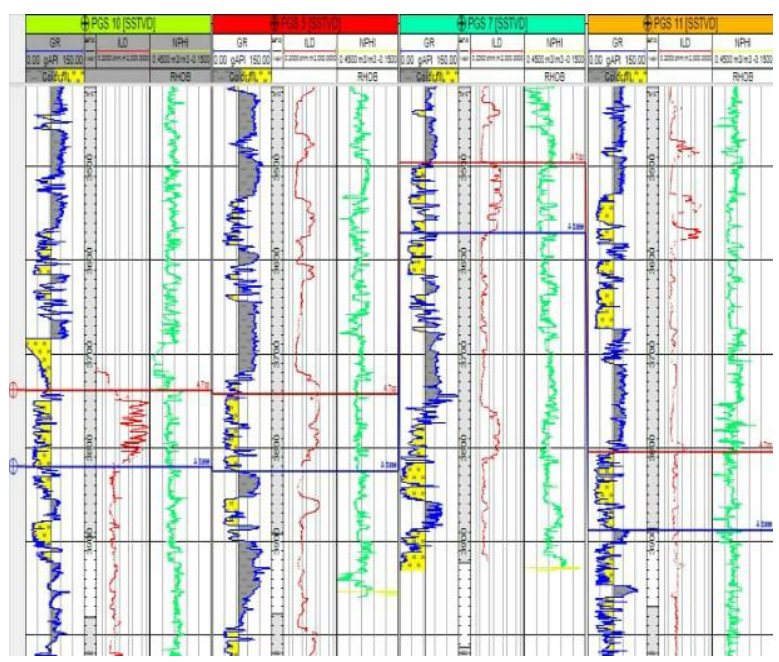

Figure 6: Stratigraphic correlation of wells in NW-SE direction in PGS 5, PGS 7, PGS 10, PGS 11 order, showing gamm ray log, resistiviy log, density and neutron log.

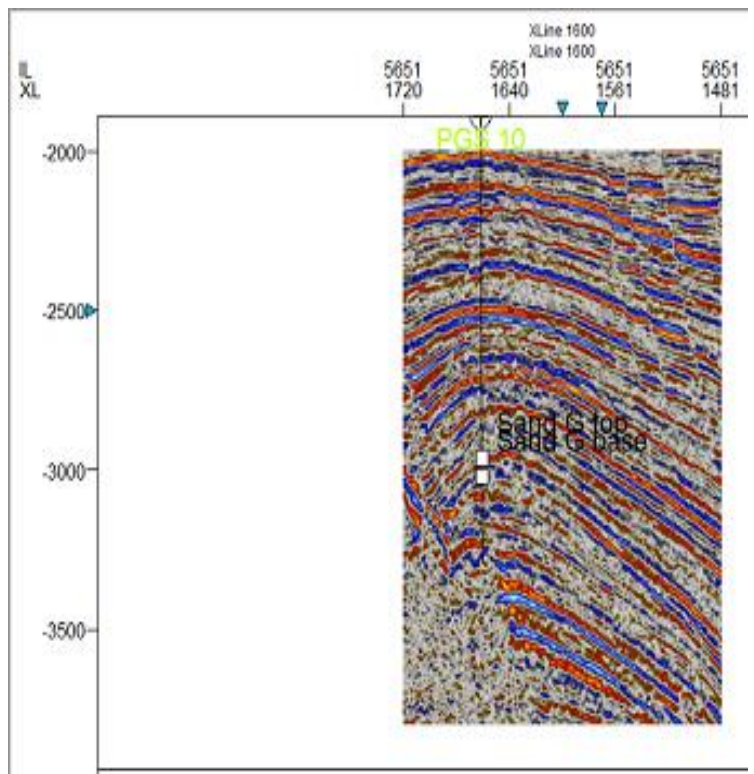


ISSN: 2576-6732 (Print)

Figure 7: Well to Seismic Tie of Sand G

\subsection{Petrophysical parameters of reservoir $\mathrm{G}$ through the wells}

Table 1: Petrophysical parameters calculated

\begin{tabular}{|l|l|l|l|l|}
\hline Reservoir & N/G Res & Phl Pay & Sw & Vshl \\
\hline G & 0.81 & 0.22 & 0.25 & 0.20 \\
\hline
\end{tabular}

Table 2: Summary of the well data and corresponding logs

\begin{tabular}{|l|l|l|}
\hline WELLS & DEPTH REGISTRATION & AVAILABLE LOGS \\
\hline PGS 5 & $46 \mathrm{ft}-12006 \mathrm{ft}$ & GR,ILD,LLD.MSFL,NPHI,RHOB,CALI,SP \\
\hline PGS 7 & $120 \mathrm{ft}-11907 \mathrm{ft}$ & GR,ILD,LLD,MSFL,NPHI,RHOB,CALI,SP \\
\hline PGS 10 & $36 \mathrm{ft}-11708 \mathrm{ft}$ & GR,ILD,LLD,MSF,NPHI,RHOB,CALI,SP \\
\hline PGS 11 & $51 \mathrm{ft}-11900 \mathrm{ft}$ & GR,ILD,LLD,MSFL,NPHI,RHOB,CALI,SP and check shot data \\
\hline
\end{tabular}

\subsection{Seismic Interpretation}

Seismic to well tie was done using the check shot data provided for PGS 11. Figure 8 describe the horizons and corresponding time events on the seismic.

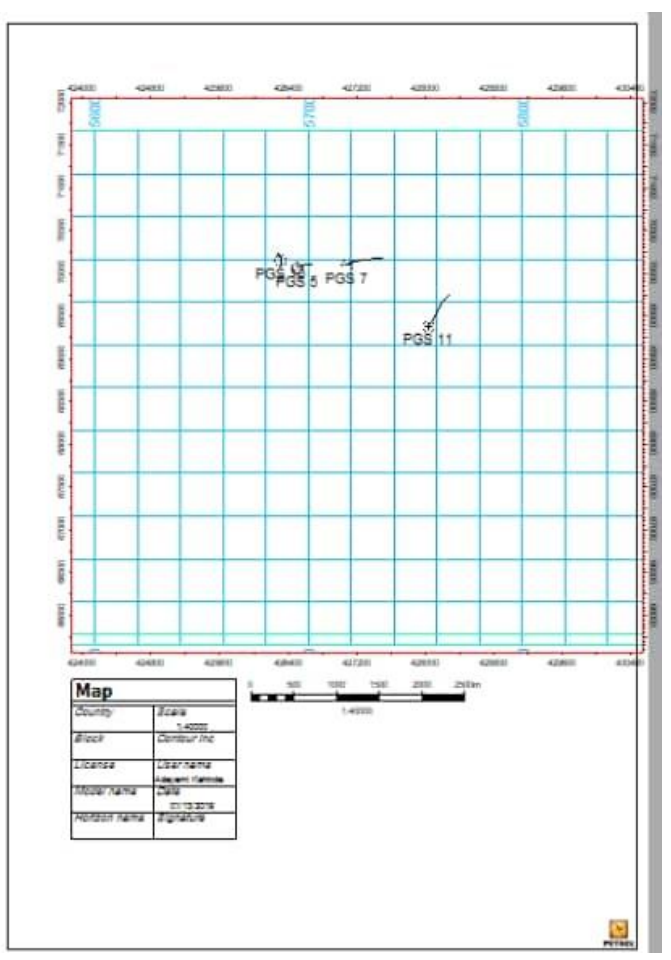

Figure 8: Base map of the study area with the well location of PGS 10, PGS 5, PGS 7, and PGS 11 respectively.

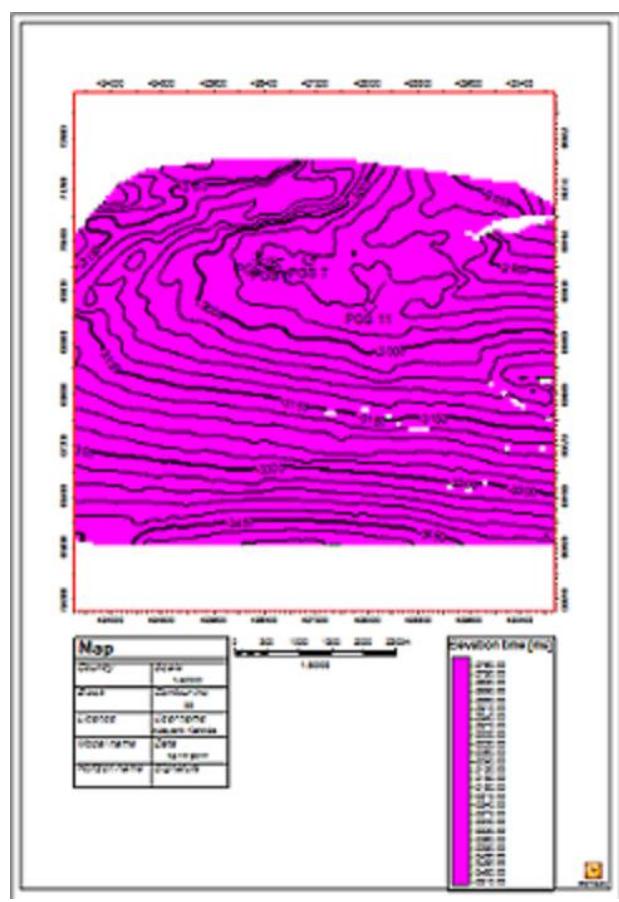


Figure 9: Seismic data imposed the on the base map

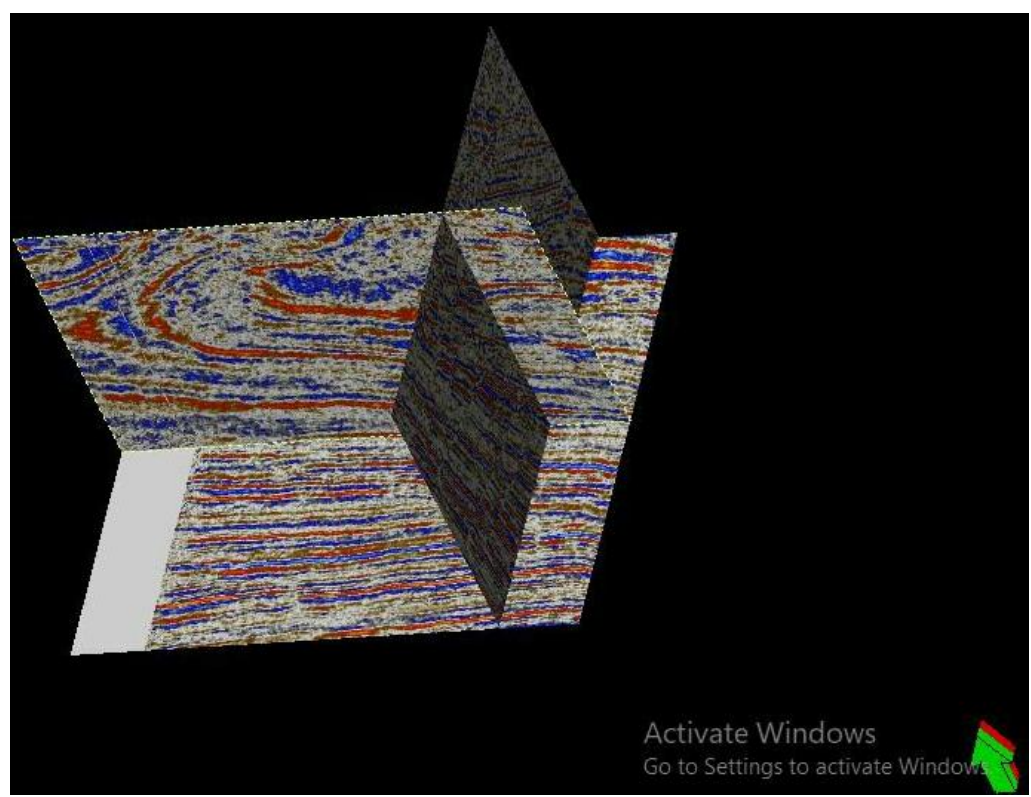

Figure 10: 3D image of the seismic dataset

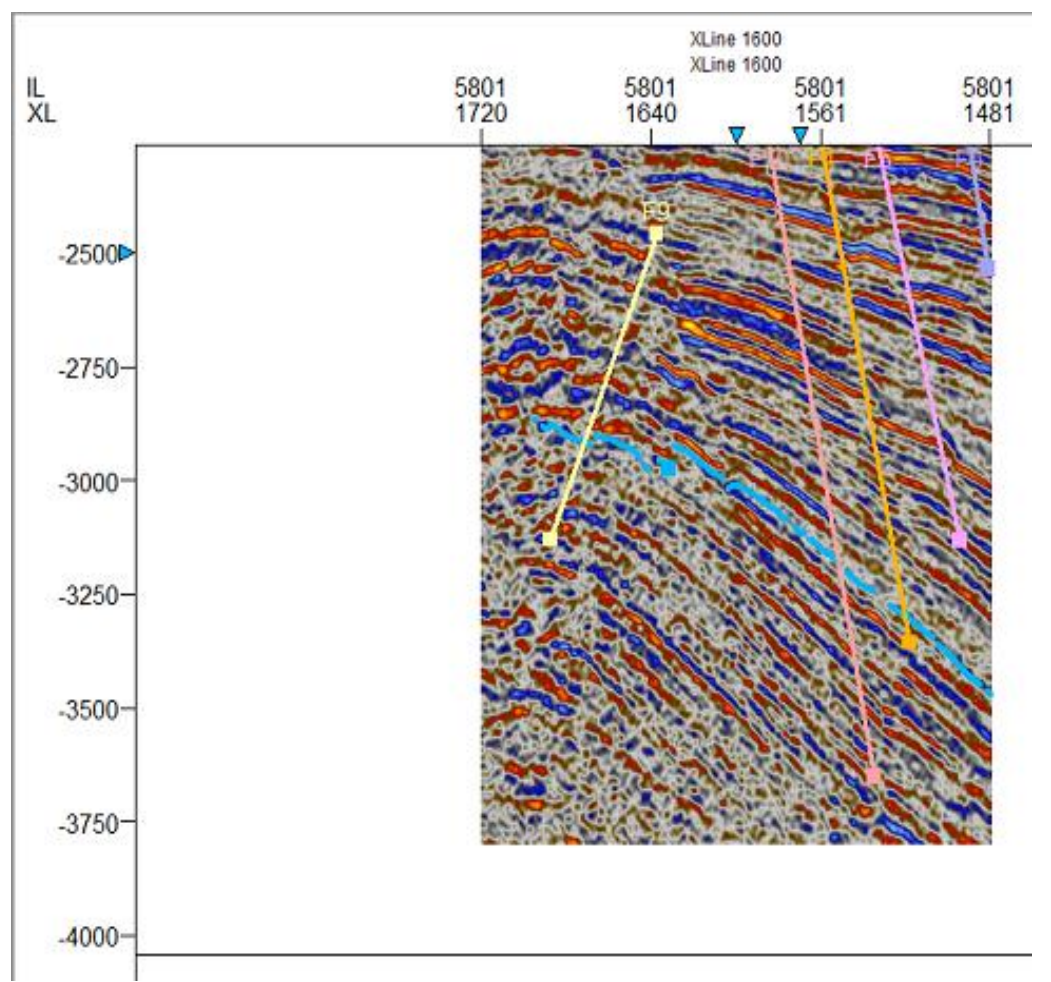

Figure 11: Arbitrary section showing interpreted horizons with hydrocarbon trapping faults F4 and F10

\subsubsection{Fault interpretation}

The structural framework was done by picking assigned faults segments on inline sections of the seismic with the trace appearing on the corresponding cross lines. These faults are represented on the seismic sections as a discontinuous reflection along a preferred orientation of reflectors or as distortion of amplitude around the fault zones. Table 3 demonstrate ten faults coded as F1, F2, F3, F4, F5, F6, F7, F8, F9, F10 were identified appearing on different inlines (figures) some extending through the extent of the field known as major regional growth faults, few flank faults appearing on few of the lines and listric crestal faults appearing within the seismic extent (Table 3). Three major regional growth faults F10, F4, F5 (Figure 8) were identified and correlated across the field forming the boundaries to the North and South of the field. The two major regional faults F10 and F4 and some other faults are dipping to the south away from the direction of sediment supply. Thus they are both regional faults while some of the other faults are dipping south, southwest, southeast, etc. South dipping crested faults F10, F9 and F4 are important trapping faults responsible for holding the hydrocarbon in wells PGS 5, PGS 7, PGS 10, and PGS 11. The hydrocarbon traps are basically fault assisted.

\subsubsection{Horizon interpretation}

A total of six horizons were interpreted across the field with both time and depth maps generated for one of the horizons. Figures show the top and surfaces maps of the horizons in time and depth.

\subsubsection{Attribute analysis}

Four attributes (amplitude, variance, acoustic impedance, root mean square) were extracted and displayed as flattened maps (slice at 1481, 1561, 1640, $1720 \mathrm{~ms}$ for each of the interpreted horizons. Root mean square (RMS) amplitude, instantaneous frequency and interval average maps were extracted on 
seismic events with pronounced bright the dim spots. These maps were used to establish the diagnostic ability of 3D seismic attribute analysis in enhancing seismic interpretation and volumetric estimation of the mid Miocene to Pliocene Agbada Formation reservoirs within the Coastal swamp depobelt, Niger Delta Structures respond to acoustic wave in different ways thus the four attributes extracted were suitable for studying subtle and sub-seismic structures missed by conventional seismic interpretation. Structural features such as closures and faults were studied in the course of this investigation. Figures 13 to 16 indicated that amplitude can be used to identify prospect on a green field where no prior exploration work has taken place and also in areas where further exploration work is required.

\subsubsection{Seismic attributes}

The amplitude attribute used in this work use the seismic signal amplitude as the basis for their computation. The RMS (root mean square amplitude) is a post-stack attribute that computes the square root of the sum of squared amplitudes divided by the number of samples within the specified window used. With this root mean square amplitude, one can measure reflectivity in order to map direct hydrocarbon indicators in a zone of interest. However, RMS is sensitive to noise as it squares every value within the window as seen in figure (Figure 11) below. The time/ horizon attribute is a post-stack attribute that measures the continuity between seismic traces in a specified window along a picked horizon. It can be used to map the lateral extent of a formation. It can also be used to see faults, channels or other discontinuous features as seen in (Figure 12) below.

Although it should be used along a specified horizon, many software packages compute this attribute along arbitrary time-slices. While the frequency attribute involves separating and classifying seismic events within each trace based on their frequency content. The application of these attributes is commonly called spectral decomposition. The starting point of spectral decomposition is to decompose each 1D trace from the time domain into its corresponding 2D representation in the time-frequency domain by means of any method of time-frequency decomposition such as: short-time Fourier transform, continuous wavelet transform, Wigner-Ville distribution, matching pursuit, among many others. Once each trace has been transformed into the time-frequency domain, a band-pass filter can be applied to view the amplitudes of seismic data at any frequency or range of frequencies as shown in (Figure 10) below.

Technically, each individual frequency or band of frequencies could be considered an attribute. The seismic data is usually filtered at various frequency ranges in order to show certain geological patterns that may not be obvious in the other frequency bands. There is an inverse relationship between the thickness of a rock layer and the corresponding peak frequency of its seismic reflection. That is, thinner rock layers are much more apparent at higher frequencies and thicker rock layers are much more apparent at lower frequencies. This can be used to qualitatively identify thinning or thickening of a rock unit in different directions. Spectral decomposition has also been widely used as a direct hydrocarbon indicator.

Table 3: Interpreted faults with corresponding seismic coverage

\begin{tabular}{|l|l|l|}
\hline FAULTS & DIP DIRECTION & INLINE COVERED \\
\hline F1 & NORTHWEST & $5700-5850$ \\
\hline F2 & NORTHWEST & $5700-5800$ \\
\hline F3 & NORTHWEST & $6100-6500$ \\
\hline F4 & SOUTHEAST & $5600-6200$ \\
\hline F5 & EAST & $5700-6200$ \\
\hline F6 & SOUTHEAST & $5765-6200$ \\
\hline F7 & SOUTHEAST & $5800-5990$ \\
\hline F8 & NORTHEAST & $5700-6100$ \\
\hline F9 & SOUTHEAST & $5850-6350$ \\
\hline F10 & SOUTHEAST & $5800-6500$ \\
\hline
\end{tabular}

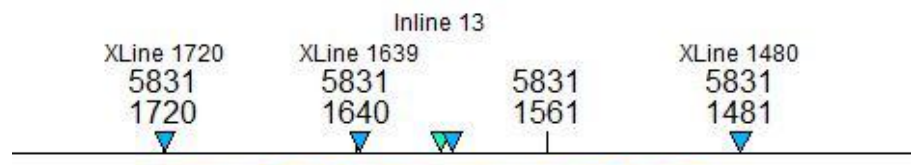

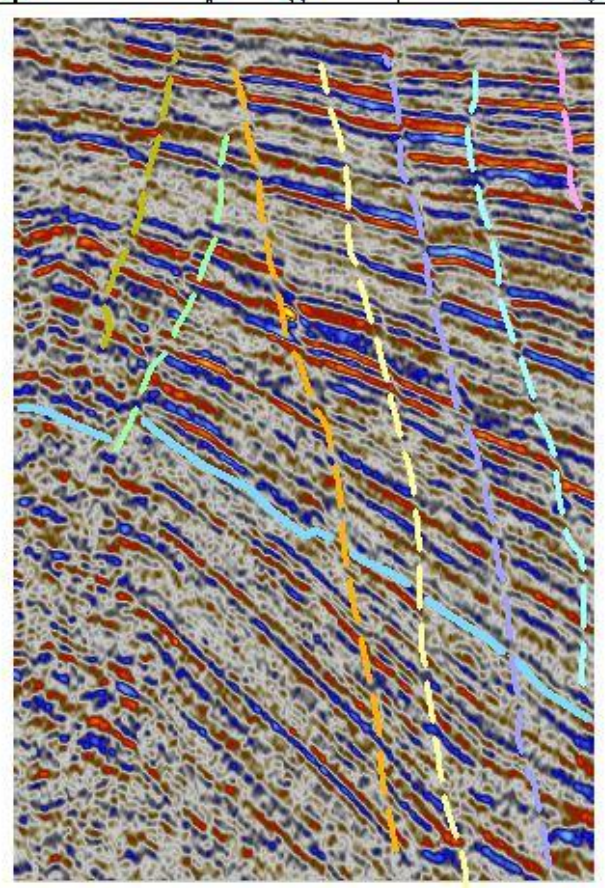


ISSN: 2576-6732 (Print)

Figure 12: Manual horizon interpretation on (Inline 5801)

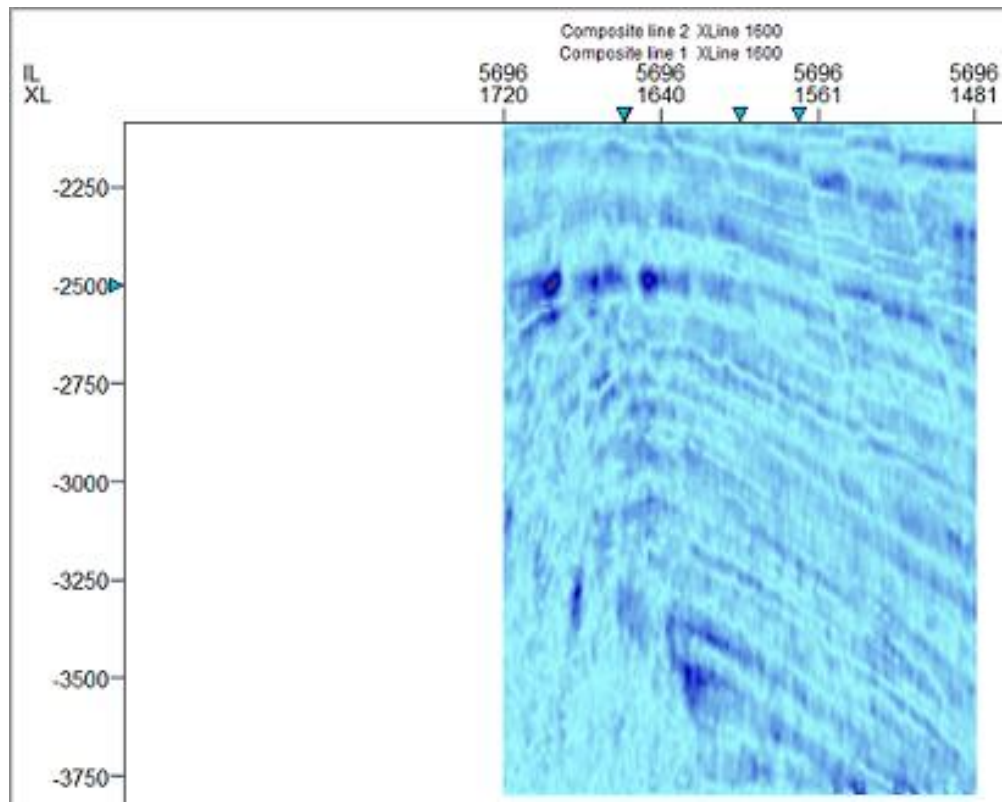

Figure 13: Seismic image viewed using the sweetness attribute.

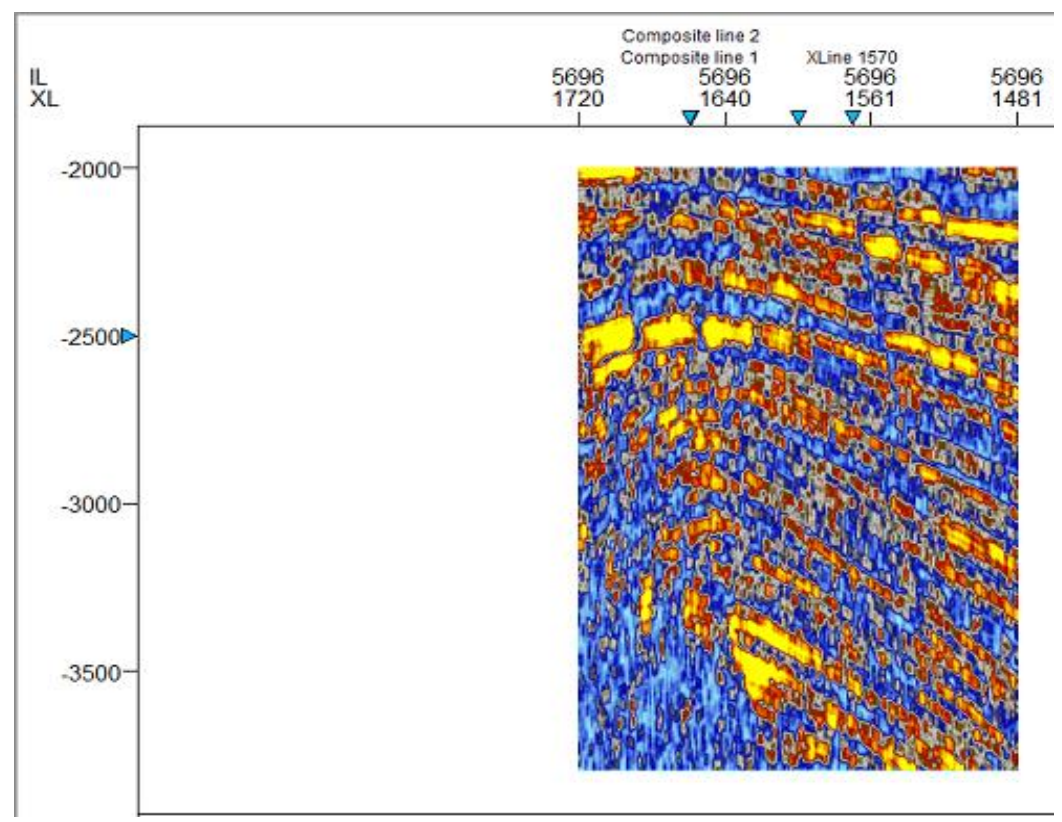

Figure 14: Seismic section (Inline 5696) using the root mean square (RMS) attribute.

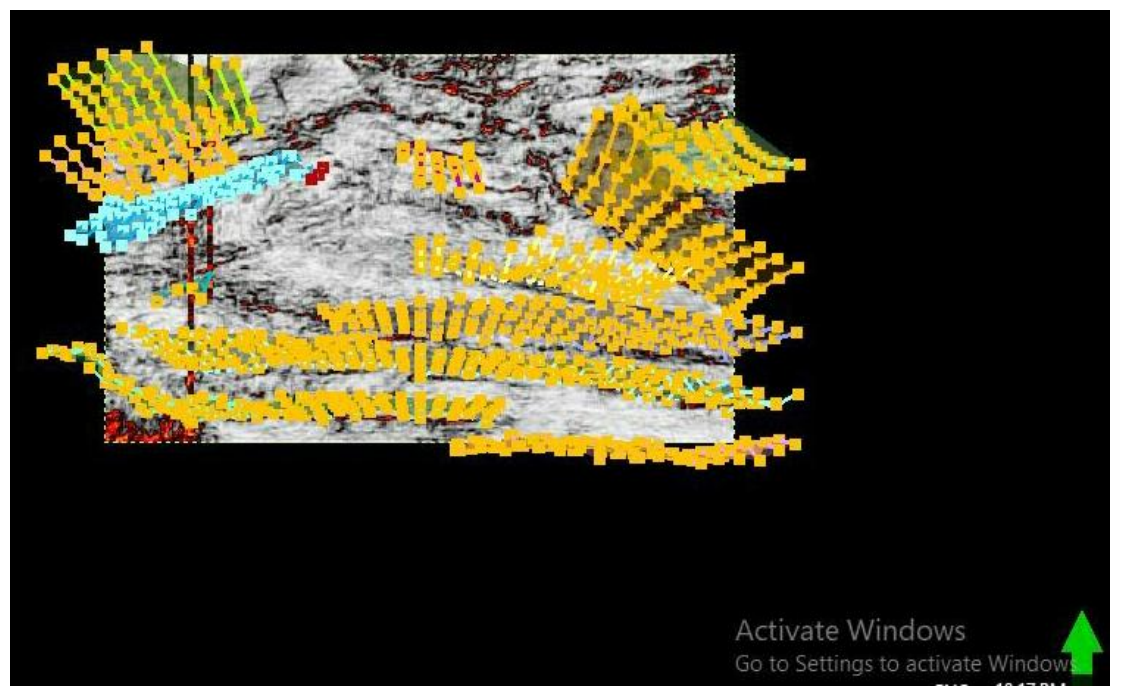

Figure 15: Seismic section using the variance attribute showing the map faults 


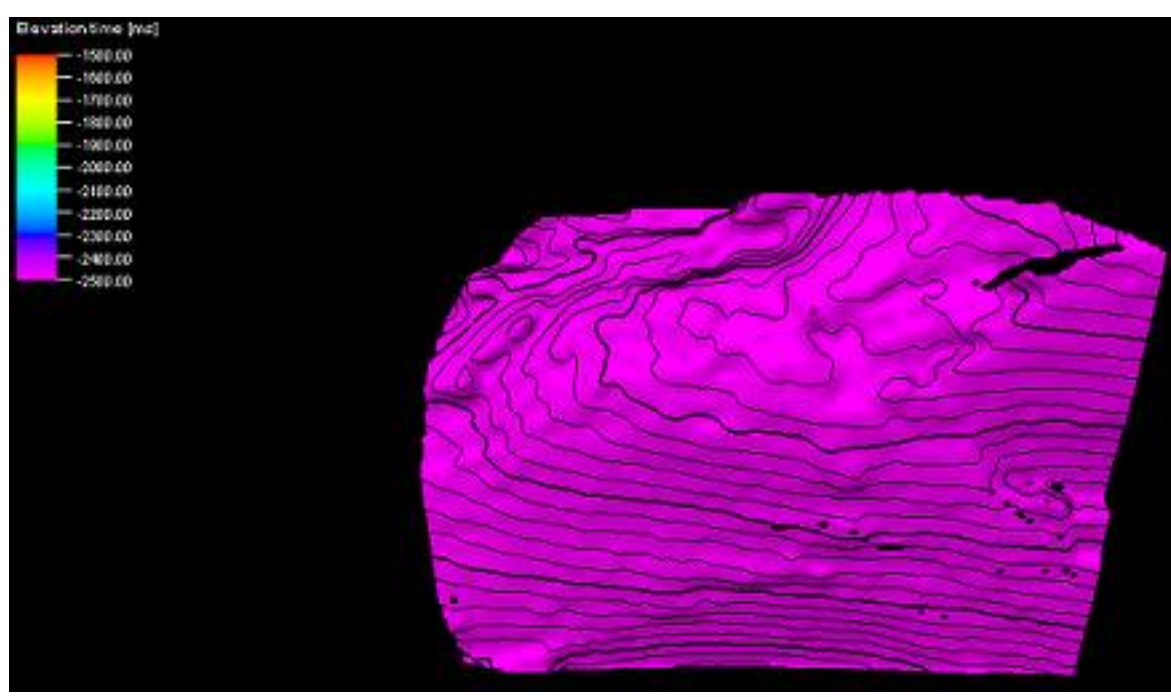

Figure 16: Structural time map of horizon showing identified closures

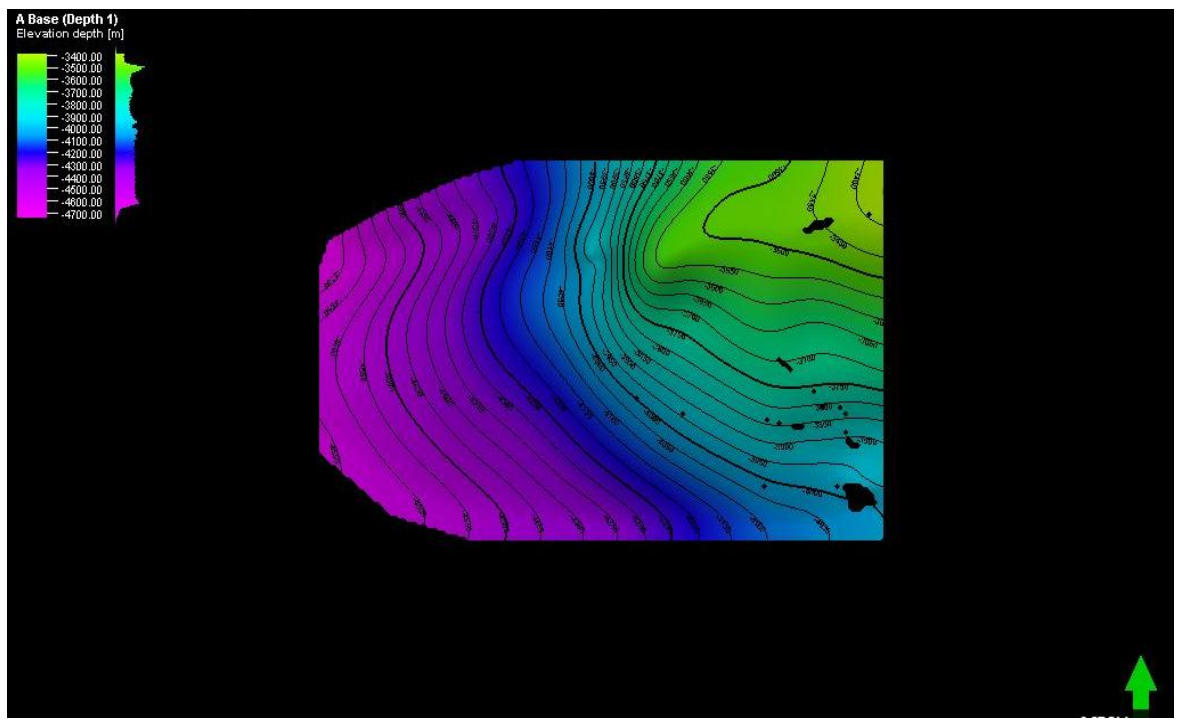

Figure 17: Structural time-depth map

\subsection{Discussion}

The relationship between well logs and well seismic surveys are visible in the matching of $\mathrm{T}$ vs. Z relation from acoustic logging well to seismic survey data, adjustment of sonic log using borehole seismic data and depth-time conversion, calculation of acoustic impedance log and reflectivity profile, construction of synthetic seismogram using an appropriate wavelet, comparative analysis of seismic traces leading to the identification of markers, combined use of logging and borehole seismic data at the well, in the vicinity of the well and beneath the well (information on structural geology, under-compaction etc.).

The presence of gas in rocks can influence the behaviour of seismic waves with detailed review of the various phenomena generally referred to a Direct Hydrocarbon Indicators (DHI's). These indicators are linked to changes in the acoustic properties of the reservoir, notably the decreases in P wave velocity with respect to the same reservoir saturated in water. The presence of hydrocarbons may be indicated by:

- Amplitude anomalies: an abnormally strong reflection (or bright spot) may be observed above the gas reservoir. This phenomenon is due to the weak acoustic impedance of gas-bearing rocks.

- Flat spots: isochronal reflections can be associated with the gas-oil or gas-water interface.

- Polarity changes which may be observed in reflections at the boundaries of the gas reservoir are due to the changes in the reflections coefficient at the top or base of the reservoir.

- Diffraction effects are produced by abrupt changes in the reflection coefficient at the top or base of the reservoir (at its lateral extremities)

- Zones of weak amplitude beneath the gas reservoir are due to the loss of energy of reflection as they traverse the gas reservoir.

- Lower frequency: a zone of low-frequency reflections may be observed within the reservoir unit. This phenomenon is due to the absorption and low velocity of acoustic waves in the gas phase.

\subsection{Conclusion}

The gamma ray, resistivity Log, Neutron and density Log revealed four lithology in this well, namely: sandstone, shaly sandstone, shaly sand and shale. The lithology correlation of the four wells, consists of sand-shale intercalation with the traces of shale sometimes found within the sand formation (using gamma ray and resistivity logs). Formation unit thickness such as average gross thickness evaluated the interval of interest across the wells with seven reservoirs identified, on the high gamma ray deflections within the sand zones. Computed petrophysical parameters of the reservoirs in each well showed that each formation has varying degree of petrophysical parameters while reservoir $\mathrm{G}$ has a prolific hydrocarbon reservoir, due to its shale volume and the clean 
sand mapped as a probable hydrocarbon reservoir. The volume of shale calculated the water saturation because shale has the capacity to bound with water which will increase the water saturation level. Petrophysically, the reservoir usually has lower density than the same lithology that surrounds the reservoir, low gamma ray, and high resistivity response.

The Formation with low density usually has high porosity which is needed to store the hydrocarbon fluid while the gamma ray responded to the reservoirs: sandstone/shaly-sandstone, the Formation has very high gamma ray response which contains more shale than the one with low gamma ray response, shale will block the interconnected pores which will reduce the effective porosity and permeability and that will prevent the hydrocarbon fluid to be stored inside the pores. The resistivity of oil and gas is higher than water, so by looking onto the well log data, a zone of interest (where cross over between RHOB-NPHI is present) is not always a reservoir if the resistivity is low. Interpretation of the 3D seismic data for locating both seismic scale and sub-seismic scale structural and stratigraphic elements has been demonstrated to be more efficient by the use of seismic attribute mapping and analysis. Variance attribute map has proved to be an appropriate tool to study fault architecture than dip attribute or any other attribute map in the study area. Therefore, to reduce the risk of drilling dry hole, resulting from missed fault by conventional seismic interpretation, seismic attribute analysis can be integrated into the standard practice of hydrocarbon Exploration and Production Company.

\section{References}

[1] T.J.A. Reijers, S.W. Petters, and C.S. Nwajide, “The Niger Delta Basin”, in Selley, R.C., ed., African Basins--Sedimentary Basin of the World 3: Amsterdam", Elsevier Science, pp. 151-172, 1997.

[2] Thomas., “Niger delta oil production, reserves, field sizes assessed”, Oil \& Gas Journal, Pp. 101-103, 1995.

[3] L.S. Smith-Rouch, K.E. Meisling, P.E. Hennings, and J.M. Armentrout, "Tectono-stratigraphic computer experiments-Nigeria example", American Association of Petroleum Geologists Bulletin Abstracts, 1996.

[4] R.C. Haack, P. Sundararaman, and J. Dahl, "Niger Delta petroleum System", in, Extended Abstracts, AAPG/ABGP Hedberg Research Symposium", Petroleum Systems of the South Atlantic Margin, November 16-19, Rio de Janeiro, Brazil, 1997.

[5] T.R. Klett, T.S. Ahlbrandt, J.W. Schmokerand, and J.L. Dolton, “Ranking of the world's oil and gas provinces by known petroleum volumes”, U.S. Geological Survey Open-file Report-97, Pp. 463, 1997.

[6] K.C. Short, and A.J. Stäuble, “Outline of geology of Niger Delta”, American Association of Petroleum Geologists Bulletin, Vol. 51, Pp. 761-779, 1965.

[7] A.A. Avbovbo, “Tertiary lithostratigraphy of Niger Delta”, American Association of Petroleum Geologists Bulletin, Vol. 62, Pp. 295-300, 1978.

[8] H. Doust, and E. Omatsola, "Niger Delta”, in, Edwards, J. D., and Santogrossi, P.A., eds., Divergent/passive Margin Basins", AAPG Memoir 48: Tulsa, American Association of Petroleum Geologists, Pp. 239-248, 1990.

[9] C.M. Ekweozor, and N.V. Okoye, "Petroleum source-bed evaluation of Tertiary Niger Delta”, American Association of Petroleum Geologists Bulletin, Vol. 64, Pp. 1251-1259, 1980.

[10] J.J. Nwachukwu, and P.I. Chukwurah, "Organic matter of Agbada Formation, Niger Delta, Nigeria", American Association of Petroleum Geologists Bulletin, Vol. 70, Pp. 48-55, 1986.

[11] P.M. Shannon, and N. Naylor, “Petroleum Basin Studies London”, Graham and Trotman Limited, Pp. 153-169, 1989.

[12] B.D. Evamy, J. Haremboure, P. Kamerling, W.A. Knaap, F.A. Molloy, and P.H. Rowlands, "Hydrocarbon habitat of Tertiary Niger Delta", American Association of Petroleum Geologists Bulletin, Vol. 62, Pp. 277-298, 1978.

[13] P. Stacher, "Present understanding of the Niger Delta hydrocarbon habitat.”, Oti, M.N., and Postma, G., eds., Geology of Deltas: Rotterdam, A.A. Balkema, Pp. 257-267, 1995.

[14] J.E. Ejedawe, S.J.L., Coker, D.O. Lambert-Aikhionbare, K.B. Alofe, F.O. Adoh, "Evolution of oil-generative window and oil and gas occurrence in Tertiary Niger Delta Basin", American Association of Petroleum Geologists, 68, Pp. 1744-1751, 1984.

[15] F.T. Beka, and M.N. Oti, "The distal offshore Niger Delta: frontier prospects of a mature petroleum province”, Oti, M.N., and Postma, G., eds., Geology of Deltas: Rotterdam, A.A. Balkema, Pp. 237-241, 1995.

[16] J.M. Hunt, "Generation and migration of petroleum from abnormally pressured fluid compartments", American Association of Petroleum Geologists Bulletin, Vol. 74, Pp. 1-12, 1990.

[17] L.B. Magoon, and W.G. Dow, "The petroleum System, in, Magoon, L.B., and Dow, W.G., eds., The Petroleum System--from Source to trap", AAPG Memoir 60: Tulsa, American Association of Petroleum Geologists, Pp. 3-24, 1994.

[18] D.O. Lambert-Aikhionbare, and A.C. Ibe, "Petroleum source-bed evaluation of the Tertiary Niger Delta: discussion”, American Association of Petroleum Geologists Bulletin, Vol. 68, Pp. 387-394, 1984. 